\title{
Trade and the Speed of Convergence
}

E. Young Song*

Sogang University

\begin{abstract}
This paper derives a convergence equation for a world integrated by trade. Factor price equalization induced by trade reduces saving in capital-scarce economies, while it exercises the opposite effect in capital-abundant economies. Thus income convergence among parametrically identical economies is slower in a world integrated by trade than in a world of autarkic economies. Under standard parameter values, the integrated world model generates low rates of convergence frequently observed in empirical studies, without resorting to a counterfactual share of capital or high adjustment costs in investment.
\end{abstract}

Keywords: convergence, factor price equalization, growth, integration, trade JEL Classification: F43, O41

\section{Introduction}

Research on income convergence exploded following the works of Mankiw, Romer, and Weil (1992) and Barro and Sala-i-Martin (1992a). These studies opened a stage for empirical research on convergence rigorously based on neoclassical growth theory. A major attraction of the approach is that the coefficients of a regression equation can be directly linked to the structural parameters of the underlying theory, enabling researchers to assess the quantitative

* Department of Economics, Sogang University, C. P. O. Box 1142, Republic of Korea.

Tel: +82-2-705-8696, Fax: +82-2-705-8180, E-mail: eysong@sogang.ac.kr 
plausibility of the theory from estimation results.

A surprising feature of this literature is that regression equations are derived from a world that is composed of autarkic economies. Many trade economists find this lack of interdependence among economies quite disturbing (Findlay, 1996). As emphasized by classical trade theory, trade in goods is effectively trade in production factors embedded in goods. A world linked by trade must show the pattern of convergence different from a world of autarkic economies.

This paper derives a convergence equation for a world integrated by trade. We build a neoclassical model of growth in a world of economies with identical preferences and technologies, and examine how the growth rates of economies with different initial conditions evolve over time under factor price equalization brought about by trade. The convergence equation that we derive for the integrated world corresponds closely to the autarkic versions obtained by Mankiw et al. (1992) and Barro and Sala-i-Martin (1992a). As theirs, our equation can be used as a regression equation for estimating the rate of convergence, and the rate of convergence can be directly linked to the structural parameters of the model. However, there are important differences: In an integrated world, (a) the growth rates of individual economies are positively affected by the growth rate of the world; (b) the rate of convergence increases as the 
world grows faster, and (c) the rate of convergence, under conventional parameter values, is much lower in an integrated world than in a world of autarkic economies.

Given the vast literature on dynamic Heckscher-Ohlin models, this research naturally overlaps with a number of existing studies. The studies by Oniki and Uzawa (1965), Stiglitz (1970), and the works summarized in Findlay (1995) demonstrated the possibility that the gap between a rich and a poor economy widens with trade. However, these results are dependent on the assumption that poor countries are poor because they have inherently high subjective discount rates. More closely related to our paper are the studies by Chen (1992), Ventura (1997) and Atkeson and Kehoe (2000). As our paper, these studies investigate the world of economies with identical time preference, and show that the difference in capital-labor ratio among economies will persist under factor price equalization. However, none of these studies derive a convergence equation and express the rate of convergence as a function of model parameters.

Researchers of convergence were bewildered by the fact that neoclassical growth theory, under plausible parameter values, overpredicts the rate of convergence by a big margin. To reduce the rate of convergence predicted by the model, various strategies had been adopted. Mankiw et al. (1992) and Barro et al. (1995) assumed a counterfactually large share of capital in production. They justified this assumption by arguing that capital should be interpreted as 
including both physical and human capital. However, if we model human capital accumulation in a more rigorous way, the rate of convergence considerably increases, worsening the overprediction problem (Ortigueira and Santos, 1997). Duczynski (2002) introduces adjustment costs in investment to slow down convergence. However, adjustment costs are difficult to observe and hard to calibrate. Our integrated world model generates low rates of convergence frequently observed in data without imposing an extraneous assumption or restriction.

This paper is organized as follows. In Section II, we describe the model of a world integrated by trade and make some general observations. In Section III, we calculate the rate of convergence predicted by the model under Cobb-Douglas technology. In Section IV, we conclude.

\section{General Dynamics}

A closed economy produces a final good and two intermediate goods, using capital and labor.

The representative household has the following objective function:

$$
\begin{array}{ll}
\operatorname{Max} & \int_{0}^{\infty} \frac{1}{1-\theta} C^{1-\theta} \exp [-(\rho-n) t] d t \\
\text { s.t. } & \dot{K}=R K+W H-C-(n+\delta) K, \\
& \dot{H}=g H .
\end{array}
$$


$1 / \theta$ is the intertemporal rate of substitution and $\rho$ is the subjective discount rate. The number of workers, which we will denote by $L$, grows at the rate of $n$. We use $C$ to denote consumption per worker, $K$ to denote physical capital per worker, and $H$ to denote human capital per worker. Let $R$ and $W$ be the rental price of physical capital and the wage rate per human capital. Physical capital depreciates at the rate of $\delta$ and human capital per worker grows at an exogenous rate of g. ${ }^{1}$ To ensure that utility is bounded, we assume that

$$
\rho-n+(\theta-1) g>0
$$

Let us use small letters to denote quantities per effective worker: $k$ is equal to $K / H$ and $c$ is equal to $C / H$. Using this notation, we can express the solution for (1) in the following way:

$$
\begin{aligned}
& \dot{c}=\left[\frac{1}{\theta}(R-\delta-\rho)-g\right] c, \\
& \dot{k}=(R-\delta-n-g) k+W-c, \\
& \lim _{t \rightarrow \infty} k c^{-\theta} e^{-[\rho-n+(\theta-1) g] t}=0 .
\end{aligned}
$$

We adopt the production structure introduced by Corden (1971) and recently used by Ventura (1997). Competitive firms produce a final good $Y$ by bundling two intermediate goods, 1 and 2. No capital or labor is used in bundling. The bundling technology can be described as a CRS production function with diminishing marginal products. Let the unit cost of the final good

\footnotetext{
${ }^{1}$ In a companion paper, we investigate the case where $g$ is endogenously determined by education and obt ain results very similar to the present paper's.
} 
be $e\left(p_{1}, p_{2}\right)$, where the arguments are the prices of intermediate good 1 and 2 . We take $Y$ as the numeraire:

$$
e\left(p_{1,}, p_{2}\right)=1
$$

The final good is used both for consumption and for augmenting physical capital. Thus, the price of consumption and the price of investment are both equal to unity, as we implicitly assumed in the household problem above. The choice of numeraire also implies that $R$ and $W$ are the real rental price and the real wage. The real interest rate $r$ is given by $R-\delta$.

Competitive firms produce intermediate goods 1 and 2 using the following CRS technologies with diminishing marginal products.

$$
\begin{aligned}
& Q_{1}=G_{1}\left(K_{1}, H_{1}\right), \\
& Q_{2}=G_{2}\left(K_{2}, H_{2}\right),
\end{aligned}
$$

where $Q_{j}$ denotes the output of intermediate good $j$ and $K_{1}+K_{2}=K$ and $H_{1}+H_{2}=H$. We assume that good 1 is more physical-capital-intensive than good 2. Given the prices of intermediate goods, the competitive economy allocates $K$ and $H$ such that GDP per worker $Y$, which is equal to $p_{1} Q_{1}+p_{2} Q_{2}$, is maximized. Thus $Y, Q_{1}$, and $Q_{2}$ can be expressed as functions of $p_{1}, p_{2}, K$ and $H$. Because $p_{2}$ is a decreasing function of $p_{1}$ by (6), we can drop $p_{2}$ and write these functions as $Y\left(p_{1}, K, H\right), Q_{1}\left(p_{1}, K, H\right)$ and $Q_{2}\left(p_{1}, K, H\right)$. Because these functions are linearly homogenous in $K$ 
and $H$, we can express them in per-effective-worker form as follows:

$$
\begin{aligned}
& y\left(p_{1}, k\right) \equiv Y\left(p_{1}, K, H\right) / H, \\
& q_{1}\left(p_{1}, k\right) \equiv Q_{1}\left(p_{1}, K, H\right) / H, \\
& q_{2}\left(p_{1}, k\right) \equiv Q_{2}\left(p_{1}, K, H\right) / H .
\end{aligned}
$$

We can easily obtain the following proposition.

\section{[Proposition 1]}

GDP per effective worker can be expressed as a function of capital per effective worker alone:

$$
y\left(p_{1}, k\right)=f(k)
$$

Furthermore,

$$
\begin{aligned}
& f^{\prime}(k)=R, \\
& f(k)-f^{\prime}(k) k=W . \\
& f^{\prime}(k)<0 .
\end{aligned}
$$

The proof can be found in the appendix. Using proposition 1, (3) and (4) can be written as:

$$
\begin{aligned}
\dot{c} & =\left[\frac{1}{\theta}\left(f^{\prime}(k)-\delta-\rho\right)-g\right] c, \\
\dot{k} & =f(k)-(\delta+n+g) k-c .
\end{aligned}
$$


In the following, we will focus on the case in which $f(k)$ satisfies the Inada condition. ${ }^{2}$ The economy converges to the unique steady state defined by:

$$
\begin{aligned}
& R^{*}=f^{\prime}\left(k^{*}\right)=\delta+\rho+\theta g, \\
& c^{*}=f\left(k^{*}\right)-(\delta+n+g) k^{*} .
\end{aligned}
$$

We use asterisks to denote steady state values. The steady state interest rate is given by $r^{*}=R^{*}-$ $\delta$. In short, using the function $f(k)$, our two-sector economy can be reduced to the standard onesector model known as the Ramsey-Cass-Koopmans model.

We now consider a world composed of $I$ countries. ${ }^{3}$ All countries are identical to the economy described above, except in that they have different starting levels of $K$ and $H$. Suppose that all these countries are closed. Then, denoting country by subscript $i(i=1, \ldots, I), c_{i}$ and $k_{i}$ would be governed by the same dynamics as described by (16) and (17). $k_{i}$ would converge to $k^{*}$ regardless of its initial level. In the long run, all countries would reach the same level of income per effective worker and would also attain the same level of income per worker if the initial levels of human capital were identical across countries.

Now suppose that these countries engage in costless trade of intermediate goods with each other. The final good is not traded. Capital and labor do not move across countries, and no

\footnotetext{
22 If $f(k) / k$ has a lower bound greater than $\delta+n+g$, the economy asymtotically behaves like an $A K$-type endo genous growth model. The Inada condition precludes this possibility.

3 Although we call them countries, they can be states, prefectures, or regions in a single country. We ma $\mathrm{y}$ prefer the latter interpretation because factor price equalization is more likely to hold in this environment. 
international lending and borrowing occurs. ${ }^{4}$ Let $\sigma_{i}$ be the share of country $i$ in world effective labor:

$$
\sigma_{i}=H_{i} L_{i} / \sum_{j} H_{j} L_{j}
$$

$L_{i}$ is the number of workers in country $i$. This share is constant, given our assumption that the growth rates of population and human capital are identical everywhere. We denote world variables by dropping country subscripts. For example,

$$
\begin{aligned}
& c=\sum_{i} \sigma_{i} c_{i}, \\
& k=\sum_{i} \sigma_{i} k_{i} .
\end{aligned}
$$

Note that using proposition $1, R / W$ can be expressed as a function of $k$. Given $R / W$, we can determine the values of $K_{1} / H_{1}$ and $K_{2} / H_{2}$ that minimize the costs of producing intermediate good 1 and 2. Let us call these capital intensities $k_{1}(k)$ and $k_{2}(k)$. We assume that

$$
k_{2}(k) \leq k_{i} \leq k_{1}(k) \text { for any } i \text {. }
$$

In other words, the factor endowments of all countries are inside the cone defined by $k_{1}(k)$ and $k_{2}(k)$. It is well-known in international trade (Dixit and Norman, 1980) that if this condition is satisfied, free trade among I countries replicates the equilibrium of the integrated economy, a

\footnotetext{
4 These assumptions are not restrictive in the context of our model. Producing the final good does not co st any resources and can occur anywhere without affecting equilibrium. Factor prices are equalized across c ountries and households are indifferent between investing at home and lending abroad. Thus, the amount of international lending is indeterminate. Factors can move across countries changing their levels of output, b ut their levels of income are not affected. Infinitesimal costs in cross-border movements of factors would b e enough to confine them within borders.
} 
hypothetical closed economy endowed with physical capital of $\sum_{i} K_{i}$ and effective labor of $\sum_{i} H_{i} L_{i}$. Goods and factors prices are equalized across countries. There is no specialization in production and all countries produce two intermediate goods. If country $i$ is abundant in physical capital $\left(k_{i}>k\right)$, it exports the capital-intensive intermediate good 1 . If country $i$ is abundant in labor $\left(k_{i}<k\right)$, it exports the labor-intensive intermediate good 2. $c$ and $k$ follow the same path as given by (16) and (17), converging to the steady state of $c^{*}$ and $k^{*}$. The world as a whole behaves just like a single closed economy.

Because factor prices are identical across countries, consumption and capital of country $i$ follow the following paths:

$$
\begin{aligned}
& \dot{c}_{i}=\left[\frac{1}{\theta}(r-\rho)-g\right] c_{i}, \\
& \dot{k}_{i}=(r-n-g) k_{i}+W-c_{i} .
\end{aligned}
$$

Using (16), (17), (24) and (25), we can prove the following proposition.

\section{[Proposition 2]}

Suppose that the world is engaged in free trade and (23) is satisfied at every moment.

Then, the capital gap between country $i$ and the world can be expressed as

$$
k_{i}(t)-k(t)=\exp \left[\int_{0}^{t}(r-n-g-\phi) d s\right]\left(k_{i}(0)-k(0)\right)
$$


$r-n-g-\phi$ is positive during transition if $k(0)<k^{*}$.

$\phi$ is the propensity to consume out of wealth. The proof can be found in the appendix.

Proposition 2 shows that the difference between country $i$ and the world will be increasing in an integrated world where output per effective worker is growing. It contains a strong implication for the relationship between trade openness and growth. Suppose that world output per effective worker is growing and a small country $i$ has $k_{i}(0)<k(0)$. If it does not trade with the world, its output will reach $y^{*}=R^{*} k^{*}+W^{*}$ in steady state. However, if it trades with the world, its long-run output will be determined by $y_{i}^{*}=R^{*} k_{i}^{*}+w^{*}$, where

$$
k_{i}^{*}=k^{*}+\exp \left[\int_{0}^{\infty}(r-n-g-\phi) d s\right]\left(k_{i}(0)-k(0)\right)<k^{*} .
$$

$y_{i}^{*}<y^{*}$ and country $i$ attains a lower long-run level of output per worker under free trade. This implies that a small country whose capital per effective worker is below (above) world average will experience a lower (higher) average growth rate under free trade than in an autarky. ${ }^{5}$

(26) also implies that

$$
k_{i}-k_{j}=\exp \left[\int_{0}^{t}(r-n-g-\phi) d s\right]\left(k_{i}(0)-k_{j}(0)\right)
$$

\footnotetext{
5 Output jumps up on the moment of opening trade due to static gains from trade. All countries gain fro $\mathrm{m}$ trade as they face the path of prices different from the autarky one. Trade stimulates consumption of a country whose capital is below average and this additional consumption reduces its long-run level of incom e.
} 
In other words, the capital gap between any two countries is ever widening during transition in an integrated world that is growing. Curiously, the widening gap in capital-labor ratio has not been noted in the literature. ${ }^{6}$ It is a direct implication of factor price equalization and the permanent income hypothesis. We obtain it under general CRS technologies and general isoelastic preferences. ${ }^{7}$ A potential problem that arises from this generalization is that (23) can be violated during transition even if it is satisfied at time zero. If this happens, our dynamics is no longer applicable. This problem can largely be avoided under Cobb-Douglas technology, as we will see in the next section.

\section{The Rate of Convergence under Cobb-Douglas Technology}

We saw in the previous section that the absolute gap in capital between countries must be widening in a growing world that is integrated by trade. However, income convergence is usually defined in terms of the gap in logarithmic income $\left|\log y_{i}-\log y_{j}\right|$, which is approximately equal to the percentage income gap $\left|y_{i} / y_{j}-1\right|$. The widening absolute gap can be consistent with convergence in logarithmic income. In this section, we show that under Cobb-Douglas technology with parameter values commonly used, the percentage gap in income indeed declines

\footnotetext{
6 Atkeson and Kehoe (2000) anticipated our result by showing that if a small country opens trade to a bi g country that already is in steady state, its growth stops on the moment of opening. Note that this stagnatio $\mathrm{n}$ occurs in our model when the world is in steady state and $r-n-g-\phi=0$.

${ }^{7}$ Ventura (1997) used a logarithmic utility function and Leontief production functions.
} 
during transition despite the widening absolute gap in capital. Trade only slows down convergence in logarithmic income.

The pattern of convergence in a world of autarkic economies is well understood for the Cobb-Douglas case. By log-linearizing the system composed of equations (16) and (17) using the production function $f(k)=A k^{\alpha}$, Barro and Sala-i-Martin (1992a) derive the following convergence equation for autarkic economies:

$$
\frac{1}{T} \log \frac{y_{i}(T)}{y_{i}(0)}=\frac{1}{T}\left(1-\exp \left[-\lambda_{c} T\right]\right) \log \frac{y_{i}^{*}}{y_{i}(0)}
$$

where

$$
\lambda_{c}=\frac{1}{2}\left[\sqrt{\left(R^{*}-\delta-n-g\right)^{2}+4(1-\alpha) \frac{R^{*}}{\theta}\left(\frac{R^{*}}{\alpha}-\delta-n-g\right)}-\left(R^{*}-\delta-n-g\right)\right] .
$$

$\lambda_{c}$ is the rate of convergence and is always positive. It measures the rate at which the gap between current income $\left(\log y_{i}\right)$ and steady state income $\left(\log y_{i}^{*}\right)$ shrinks in a single closed economy. If countries in the world are parametrically identical and if they all are in autarky,

$$
\log \frac{y_{i}(T)}{y_{j}(T)}=\exp \left[-\lambda_{c} T\right] \log \frac{y_{i}(0)}{y_{j}(0)} \text {. }
$$

Thus $\lambda_{c}$ also determines the rate at which the percentage income gap between two countries shrinks. The standard method for estimating $\lambda_{c}$ is to run a cross-country regression of equation (29). Many empirical studies estimate $\lambda_{\mathrm{c}}$ to be around the value of $.02 .^{8}$

\footnotetext{
8 In a standard cross-country regression, $y_{i}^{*}$ is allowed to vary among countries, implying conditional con vergence. In a cross-regional regression, it is frequently assumed that regions approach the same steady stat e. So many growth regressions report $\lambda_{c}$ close to 0.02 that some regard it as an empirical law. See Barro and Sala-I-Martin (2004, chaps. 11-12). However, estimation methods are controversial. Caselli, Esquivel, a 
It is well-known that neoclassical growth theory overpredicts the rate of convergence under standard parameter values. We take the following values as the benchmark case:

$$
\theta=1, \rho=0.02, \delta=0.05, n=0.01, g=0.02 \text {. }
$$

$\lambda_{c}$ is sensitive to $\alpha$, capital share of income. The upper line in Figure 1 traces the value of $\lambda_{c}$ as $\alpha$ changes from zero to 1 . At a conventional value of $\alpha$, which is around $0.30, \lambda_{c}$ is well above 0.10 . To reduce it down to $0.02, \alpha$ should be as high as 0.80 . This is the reason that Mankiw et at. (1992) suggested that $\alpha$ should be interpreted as the share of broadly defined capital, including both human and physical capital.

All this controversy proceeded with the assumption that countries in the world are completely separated from each other. We need to derive the convergence equation for a world connected by trade. We manipulate (26) to obtain the following:

$$
\frac{k_{i}(T)}{k(T)}-1=\exp \left[-\lambda_{o} T\right]\left(\frac{k_{i}(0)}{k(0)}-1\right)
$$

where

$$
\lambda_{o}=\frac{1}{T} \int_{0}^{T}\left[g_{k}-(r-n-g-\phi)\right] d t
$$

nd Lefort (1996), Islam (1995), and many others use variants of fixed-effects panel estimation and find tha $\mathrm{t} \lambda_{c}$ is far greater than 0.02 . The panel estimations eliminate omitted variable bias, but also introduce stron g upward bias due to measurement errors. See Durlauf, Johnson, and Temple (2005) and Hauk and Waczia rg (2004) for an evaluation of this controversy. 


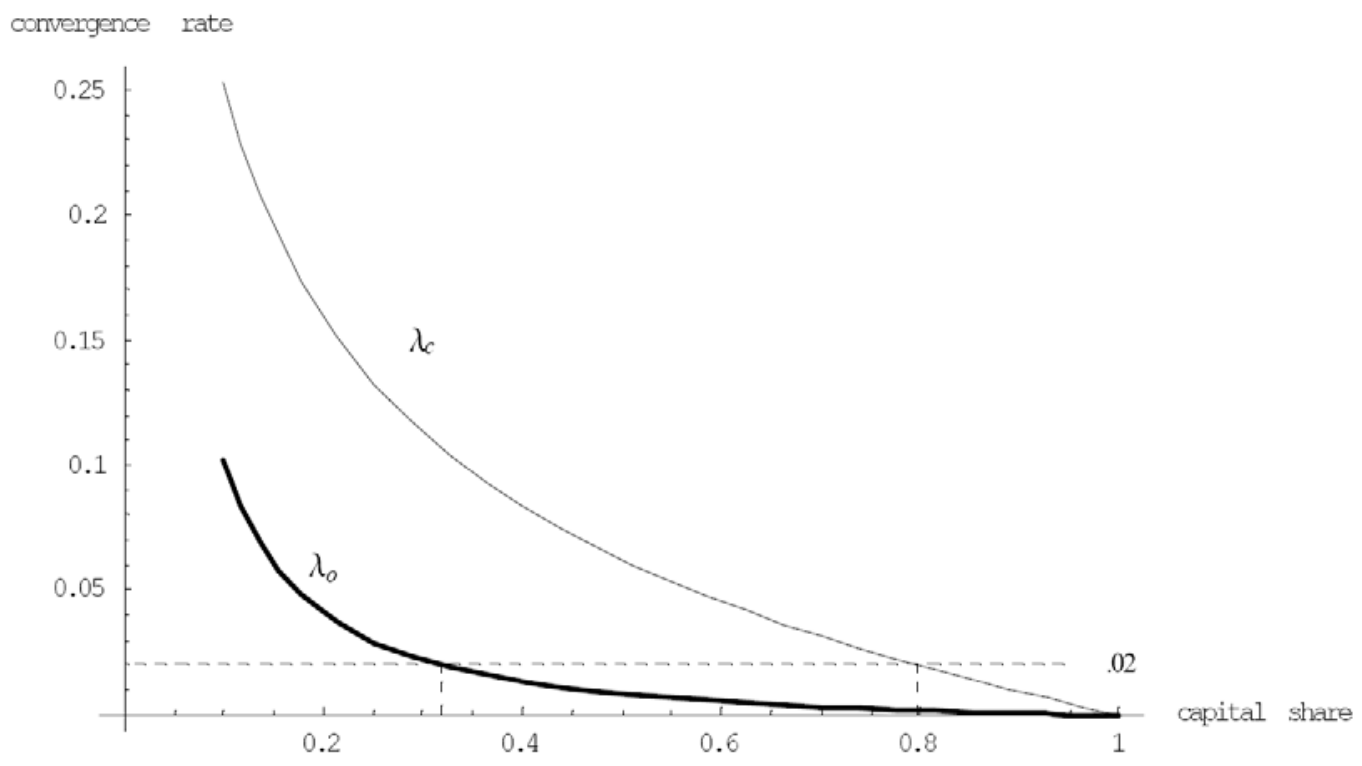

Figure 1. Rate of Convergence in the Neoclassical Model

We use $g_{k}$ to denote the growth rate of $k$. Using the fact that $y_{i}=R k_{i}+w$ and (33), we can convert

(33) into an equation for output:

$$
\frac{y_{i}(T)}{y(T)}-1=\exp \left[\int_{0}^{T}\left(r-n-g-\phi+g_{R}-g_{y}\right) d s\right]\left(\frac{y_{i}(0)}{y(0)}-1\right) .
$$

The following proposition is useful for dealing with our two-sector economy.

\section{[Proposition 3]}

Suppose that the production functions for the final good and the two intermediate goods are given by the following Cobb-Douglas functions. 


$$
\begin{aligned}
& Y=A_{f} Q_{1}^{m} Q_{2}^{1-m}, \\
& Q_{j}=A_{j} K_{j}^{\alpha_{j}}\left(H_{j}\right)^{1-\alpha_{j}}(j=1,2) .
\end{aligned}
$$

Then

$$
f(k)=A k^{\alpha},
$$

where $A$ is a positive constant and $\alpha=m \alpha_{1}+(1-m) \alpha_{2}$.

The proof is in the Appendix. The result is convenient for us because we can interpret the aggregate Cobb-Douglas production function of Barro and Sala-i-Martin (1992a) as the one derived from our two-sector economy. Then we can make a direct comparison between their results and ours. With the Cobb-Douglas assumption, $R k / y$ is constant at $\alpha$. Thus, $g_{R}+g_{k}=g_{y}$. From (34) and (35),

$$
\frac{y_{i}(T)}{y(T)}-1=\exp \left[-\lambda_{o} T\right]\left(\frac{y_{i}(0)}{y(0)}-1\right)
$$

Using the Taylor approximation that $\log y_{i} / y \approx y_{i} / y-1$ and rearranging terms, (39) can be written as:

$$
\frac{1}{T} \log \frac{y_{i}(T)}{y_{i}(0)} \approx \frac{1}{T} \log \frac{y(T)}{y(0)}+\frac{1}{T}\left(1-\exp \left[-\lambda_{o} T\right]\right) \log \frac{y(0)}{y_{i}(0)} .
$$

Compared with the convergence equation for autarkic countries, we can note two differences.

First, the growth rate of country $i$ now depends on the world growth rate, $1 / T \log y(T) / y(0)$. 
Second, we have $y(0)$ in place of $y_{i} *^{9}$ In a cross-country regression where the world growth rate and the initial world output can be treated as constant, we can estimate $\lambda_{o}$ using the same regression equation that is used in estimating $\lambda_{c}$. Thus in standard convergence regressions using data from economies connected by trade, researchers are likely to obtain estimates for $\lambda_{o}$, not $\lambda_{c}$. This misappropriation would be more likely when a regression is over regions in a single country, which is far more likely to be integrated by trade.

To determine the sign of $\lambda_{o}$, we prove the following proposition in the Appendix.

\section{[Proposition 4]}

In the two-sector economy where all the production functions are of Cobb-Douglas form and capital per effective worker is growing, $\lambda_{o}>0$ if and only if

$$
\frac{R^{*}}{\theta}>\alpha(\delta+n+g)
$$

With this proposition at hand, we go back to the question whether condition (23) will be violated. We can easily show that under Cobb-Douglas technology, $k_{2} / k$ and $k_{1} / k$ are constant. Thus, if $\lambda_{o}$ $>0$, by (33) $\left|k_{i} / k-1\right|$ decreases during transition, and (23) will never be violated if it is satisfied at time zero. Using (2) and (18), we can easily see that (41) always holds with $\theta=1$. If

\footnotetext{
9 We show below an additional difference: the rate of convergence is an increasing function of the world
} growth rate. 
$\theta=2$, with the other parameters at the benchmark levels, the condition holds for $\alpha<.69$. With $\theta$ $=3$, the condition holds for $\alpha<.54$. Thus under parameter values commonly used, the percentage income gaps will be shrinking during transition. In addition, factor price equalization will hold throughout transition once it holds at the initial moment.

To obtain a numerical value of $\lambda_{o}$, we first examine the case of $\theta=1$. In this case, $\phi=\rho-n$ and $g_{k}-(r-n-g-\phi)=g_{k}-g_{c}$. Because $y=A k^{a}, g_{k}=\frac{1}{\alpha} g_{y}$. We can show that $g_{c}=\frac{1-\alpha}{\lambda_{c}} \frac{R^{*}}{\theta} \frac{1}{\alpha} g_{y}$ on the convergent path of the log-linearized system. Plugging these equations into (34), we find

$$
\lambda_{o}=\frac{1}{\alpha}\left(1-\frac{1-\alpha}{\lambda_{c}} R^{*}\right) x
$$

where

$$
x=\frac{1}{T} \log \frac{y(T)}{y(0)}
$$

The rate of convergence is increasing in $x$, the growth rate of world output per effective worker.

$\lambda_{o}$ under various parameter values can be calculated from (42), once we know the value of $x$, which can be obtained from data. According to the Penn World Table and Barro and Lee (2001), world output grew at the annual rate of 0.0385 and world effective workers grew at the annual rate of 0.023 between 1960 and 1990. Thus $x$ for the world economy is given by .0155 and we use 0.015 as the value of $x{ }^{10}$ The lower line of Figure 1 traces the value of $\lambda_{o}$ as $\alpha$ changes. The

\footnotetext{
${ }^{10}$ The corresponding value for the US economy is 0.012 . We can use this value of $x$ if we study the
} 
rate of convergence in the integrated world is much lower than that in the world of autarkic economies. To have the rate of convergence equal to 0.02 , we need $\alpha=0.32$, which is close to the shares of physical capital observed in most countries.

For $\theta \neq 1$, we cannot obtain a simple formula like (42) as $\phi$ depends on the future path of the interest rate. In this case, we numerically simulate the model to obtain $\lambda_{o}$. We obtain the convergent paths of $k$ and $r$ and directly calculate the value of the integral in equation (34) on the paths. We select the initial value of $k$ such that $x$ is equal to 0.015 . The results for the cases where $\theta=2$ and $\theta=3$ are reported in Table 1 . We find again that the rate of convergence is much lower in an integrated world than in a world of autarkic economies. Increasing the value of $x$ reduces the difference, but unless we adopt an absurdly large value of $x$, the order does not change.

We can see that with a lower intertemporal rate of substitution, the rate of convergence became somewhat lower compared to the case where $\theta=1$. With $\theta=2, \lambda_{o}=0.02$ for $\alpha=0.025$. With $\theta=3, \lambda_{o}=0.02$ for $\alpha=0.022$. As we expected, $\lambda_{o}$ becomes negative for $\alpha>0.69$ with $\theta=$ 2, and for $\alpha>0.54$ with $\theta=3$. However, these negative values are virtually zero. Thus we do not have to worry about the possibility that condition (23) will be violated during transition even when $\lambda_{o}$ is negative. We experimented with different choices for the values of $\rho, \delta$, $n$, or $g$, but we found that the results in table 1 are not sensitive to changes in their values. convergence among the US states. 
Table 1--Simulation Results for the Neoclassical Model

\begin{tabular}{lrrrrr}
\hline & \multicolumn{2}{c}{$\theta=2$} & & \multicolumn{3}{c}{$\theta=3$} \\
\cline { 2 - 3 } \cline { 5 - 5 } & $\lambda_{c}$ & $\lambda_{o}$ & & $\lambda_{c}$ & $\lambda_{o}$ \\
\hline 0.1 & 0.265 & 0.098 & & 0.249 & 0.085 \\
0.2 & 0.160 & 0.032 & & 0.147 & 0.024 \\
0.3 & 0.109 & 0.014 & & 0.099 & 0.009 \\
0.4 & 0.078 & 0.006 & & 0.070 & 0.003 \\
0.5 & 0.056 & 0.003 & & 0.049 & 0.001 \\
0.6 & 0.040 & 0.001 & & 0.034 & -0.000 \\
0.7 & 0.027 & -0.000 & & 0.023 & -0.001 \\
0.8 & 0.016 & -0.000 & & 0.013 & -0.000 \\
0.9 & 0.007 & -0.000 & & 0.006 & -0.000 \\
\hline
\end{tabular}

\section{Conclusion}

Many believe that income convergence among countries is an overresearched topic. We can easily understand why, seeing the vast literature developed around this single topic. Nevertheless, it still is surprising that the key theory that generated all this controversy has been derived in the absence of trade among countries. This paper attempts to fill this remaining hole. We derive the convergence equation for a world integrated by trade by combining the text book models of trade and growth. We find that there is a general tendency that the absolute gaps in capital-labor ratio 
between countries widen during transition. We also find that these widening gaps are compatible with convergence in logarithmic income, and only reduce the speed of convergence. Our approach is superior to the conventional approach based on autarkic economies in that our model predicts the rate of convergence close to observed values, under standard parameter values and without imposing arbitrary assumptions.

This paper may provide some theoretical support for the studies such as Rodriguez and Rodrik (2000) and Slaughter (2001), who argued that no robust evidence exists that trade speeds up convergence. However, this paper has no intention to argue that trade will actually slow down convergence in the real world. The model that we use is highly stylized and fails to reflect many important aspects of growth, most seriously specialization and technology spillovers. However, anyone who would like to build a compelling theoretical argument that trade speeds up the growth of poor countries will have to fight against the forces identified by this paper.

\section{References}

Atkeson, A. and Kehoe, P. J. (2000), "Paths of Development for Early- and Late-Boomers in a Dynamic Heckscher-Ohlin Model,” Federal Reserve Bank of Minneapolis Staff Report 256.

Barro, R. J. and Lee, J. (2001), "International Data on Educational Attainment: Updates and Implications," Oxford Economic Papers 53: 541-563.

Barro, R. J., Mankiw, N. G.., and Sala-i-Martin, X. (1995), "Capital Mobility in Neoclassical Models of Growth,” American Economic Review 85: 103-115. 
Barro, R. J. and Sala-i-Martin, X. (1992a), “Convergence,” Journal of Political Economy 100: 223-251.

(1992b), "Regional Growth and Migration: A Japan-United States Comparison," Journal of the Japanese and International Economics 6: 312-346.

(2004), Economic Growth. 2nd ed. Cambridge: MIT Press.

Bond, E., Wang W., P., and Yip, C. K. (1996), “A General Two Sector Model of Endogenous Growth with Human and Physical Capital,” Journal of Economic Theory 68: 149-173.

Caballé, J. and Santos, M. S. (1993), “On Endogenous Growth with Physical and Human Capital,” Journal of Political Economy 101: 1042-1067.

Caselli, F., Esquivel, G., and Lefort, F. (1996), "Reopening the Convergence Debate: A New Look at Cross-Country Growth Empirics,” Journal of Economic Growth 1: 363-390.

Chen, Z. (1992): “Long-Run Equilibria in a Dynamic Heckscher-Ohlin Model,” Canadian Journal of Economics 25: 923-943

Corden, W. M. (1971), “The Effects of Trade on the Rate of Growth,” in Bhagwati, J., Jones, R., Mundell, R. and Vanek, J., eds., Trade, Balance of Payments and Growth, Amsterdam: North-Holland.

Dixit, A. K. and V. Norman (1980), Theory of International Trade, Cambridge: Cambridge University Press.

Duczynski, P. (2002), “Adjustment Costs in a Two-capital Growth Model,” Journal of Economic Dynamics and Control 26: 837-850.

Durlauf, S., Johnson, P., and Temple, J. (2005), "Growth Econometrics," in Aghion, P. and Durlauf, S. eds., Handbook of Economic Growth, volume 1, New York: Elsevier.

Findlay, R. (1995), Factor Proportion, Trade and Growth, Cambridge: MIT Press.

(1996), "Modeling Global Interdependence: Centers, Peripheries and Frontiers," American Economic Review 86: 47-51.

Hauk, W. and Wacziarg, R. (2004), "A Monte Carlo Study of Growth Regressions," NBER Technical Working Papers No. 0296, National Bureau of Economic Research.

Heston A., Summers R., and Aten, B. (2002), Penn World Table 6.1, Center for International Comparisons at the University of Pennsylvania.

Islam, N. (1995), "Growth Empirics: A Panel Data Approach," Quarterly Journal of Economics 110: 1127-1170. 
Mankiw, N. G., Romer, D., and Weil, D. N. (1992), “A Contribution to the Empirics of Economic Growth,” Quarterly Journal of Economics 107: 407-437.

Mulligan, C. B. and Sala-i-Martin, X. (1993), “Transitional Dynamics in Two-Sector Models of Endogenous Growth,” Quarterly Journal of Economics 108: 737-773.

Oniki, H. and Uzawa, H. (1965), "Patterns of Trade and Investment in a Dynamic Model of International Trade,” Review of Economic Studies 32: 15-38.

Ortigueira, S. and Santos, M. S. (1997), "On the Speed of Convergence in Endogenous Growth Models,” American Economic Review 87: 383-399.

Rodriguez, F. and Rodrik, D. (2000), "Trade Policy and Economic Growth: A Skeptic's Guide to the Cross-National Evidence," in Bernanke, B. S. and Rogoff, K., eds., NBER Macroeconomics Annual 2000, Cambridge: MIT Press.

Stiglitz, J. (1970), “Factor Price Equalization in a Dynamic Economy,” Journal of Political Economy 78: 456-488.

Slaughter, M. J. (2001), "Trade Liberalization and Per Capita Income Convergence: A Difference-in-Differences Analysis," Journal of International Economics 55: 203-228.

Ventura, J. (1997), “Growth and Interdependence,” Quarterly Journal of Economics 107: 57-84 


\section{Mathematical Appendix}

\section{[Proof for Proposition 1]}

The competitive two-sector economy allocates resources as if it solves the following problem.

$$
\begin{gathered}
y=v\left(p_{1}, p_{2}, k\right) \equiv \underset{K_{1}, K_{2}, H_{1}, H_{2}}{\operatorname{Max}} p_{1} G_{1}\left(K_{1}, H_{1}\right)+p_{2} G_{2}\left(K_{2}, H_{2}\right) \\
\text { s.t. } K_{1}+K_{2} \leq k, \\
H_{1}+H_{2} \leq 1 .
\end{gathered}
$$

Using the envelope theorem, we can show that

$$
\frac{\partial v}{\partial p_{1}}=q_{1}, \frac{\partial v}{\partial p_{2}}=q_{2}, \frac{\partial v}{\partial k}=R
$$

Let $e_{j}$ be the partial derivative of $e$ with respect to $p_{j}$. For each intermediate good, output must be equal to domestic demand. Using Shepherd's lemma, this condition can be expressed as

$$
\frac{q_{1}\left(p_{1}, k\right)}{q_{2}\left(p_{1}, k\right)}=\frac{e_{1}\left(p_{1}, p_{2}\right)}{e_{2}\left(p_{1}, p_{2}\right)}
$$

The left-hand side of (A3) is the relative supply of intermediate good 1 and the right-hand side is the relative demand. Recall that by (6), $p_{2}$ is a decreasing function of $p_{1}$. Then we can easily show that the relative supply is increasing in $p_{1}$ and the relative demand is decreasing in $p_{1}$. Thus (A3) implicitly defines $p_{1}$ as a decreasing function of $k$. Then we can express $v$ as a function of $k$ alone:

$$
y=v\left(p_{1}(k), p_{2}\left(p_{1}(k)\right), k\right) \equiv f(k) .
$$


From (6), $e_{1} d p_{1}+e_{2} d p_{2}=0$. Using this equation and (A2),

$$
d y=\frac{\partial v}{\partial p_{1}} d p_{1}+\frac{\partial v}{\partial p_{2}} d p_{2}+\frac{\partial v}{\partial k} d k=\left(q_{1} d p_{1}+q_{2} d p_{2}\right)+R d k=\left(\frac{q_{1}}{q_{2}}-\frac{e_{1}}{e_{2}}\right) q_{2} d p_{1}+R d k
$$

In autarky equilibrium, the term in the parenthesis is zero. Thus $d y / d k=f^{\prime}(k)=R$. Because producing the final and two intermediate goods does not generate any profits, $y=R k+W$. Thus $W=y-R k=f(k)-f^{\prime}(k) k$. Finally, using the Stolper-Samuelson theorem, we can express $R$ as an increasing function of $p_{1}$. Since $p_{1}$, in turn, is a decreasing function of $k, R=f^{\prime}(k)$ is decreasing in $k$.

\section{[Proof for Proposition 2]}

From (24) and (5), we can obtain the following consumption function:

$$
c_{i}=\phi\left(k_{i}+\eta\right)
$$

where

$$
\begin{aligned}
& \phi=1 / \int_{t}^{\infty} \exp \left[-\int_{t}^{s}\left(\left(r(u)-n-\frac{1}{\theta}(r(u)-\rho)\right) d u\right] d s,\right. \\
& \eta=\int_{t}^{\infty} W(s) \exp \left[-\int_{t}^{s}(r(u)-n-g) d u\right] d s .
\end{aligned}
$$

$\phi$ is the propensity to consume out of wealth and $\eta$ is the present value of wages. Under factor price equalization $\phi$ and $\eta$ are identical in all countries. Thus 


$$
c=\phi(k+\eta)
$$

Using (17), (25), (A6) and (A9), we obtain the following equation:

$$
k_{i}-k=\exp \left[\int_{0}^{t}(r-n-g-\phi) d s\right]\left(k_{i}(0)-k(0)\right)
$$

(A10) also implies that

$$
k_{i}-k_{j}=\exp \left[\int_{0}^{t}(r-n-g-\phi) d s\right]\left(k_{i}(0)-k_{j}(0)\right) .
$$

Suppose that $k(0)<k^{*}$ and the world economy is approaching the steady state from below.

Then $c$ and $k$ are increasing, and $r$ is decreasing during transition. By (16), $1 / \theta(r-\rho)$ is greater than $g$ during transition. Then

$$
\begin{aligned}
\frac{1}{\phi(t)} & =\int_{t}^{\infty} \exp \left[-\int_{t}^{s}\left(r(u)-n-\frac{1}{\theta}(r(u)-\rho)\right) d u\right] d s \geq \int_{t}^{\infty} \exp \left[-\int_{t}^{s}(r(u)-n-g) d u\right] d s \\
& \geq \int_{t}^{\infty} \exp \left[-\int_{t}^{s}(r(t)-n-g) d u\right] d s=\frac{1}{r(t)-n-g} .
\end{aligned}
$$

$r-n-g-\phi$ is strictly positive during transition and reaches zero in steady state.

\section{[Proof for Proposition 3]}

The unit cost functions for the final good and two intermediate goods are given by:

$$
\begin{gathered}
e\left(p_{1}, p_{2}\right)=\varepsilon_{f} p_{1}{ }^{m} p_{2}{ }^{1-m}, \\
d_{j}(R, W)=\varepsilon_{j} R^{\alpha_{j}} W^{1-\alpha_{j}}(j=1,2),
\end{gathered}
$$


where

$$
\begin{aligned}
& \varepsilon_{f}=A_{f}^{-1} m^{-m}(1-m)^{-(1-m)}, \\
& \varepsilon_{j}=A_{j}{ }^{-1} \alpha_{j}^{-\alpha_{j}}\left(1-\alpha_{j}\right)^{-\left(1-\alpha_{j}\right)} .
\end{aligned}
$$

Zero profits in the production of two intermediate goods require that $p_{j}=d_{j}(R, W)$. Plugging these equations into the numeraire constraint $e\left(p_{1}, p_{2}\right)=1$,

$$
\varepsilon_{f} \varepsilon_{1}^{m} \varepsilon_{2}^{1-m} R^{\alpha} W^{1-\alpha}=1
$$

where

$$
\alpha=m \alpha_{1}+(1-m) \alpha_{2} .
$$

Equation (A3) can be expressed as:

$$
\frac{p_{1} q_{1}}{p_{2} q_{2}}=\frac{p_{1} e_{1}}{p_{2} e_{2}}=\frac{m}{1-m}
$$

From this, we can derive the following equations.

$$
\begin{aligned}
& R=\alpha y k^{-1}, \\
& W=(1-\alpha) y .
\end{aligned}
$$

Thus $\alpha$ is equal to capital share in income. Plugging (A16) into (A14), we obtain that

$$
y=A k^{\alpha},
$$

where

$$
A=\varepsilon_{f}{ }^{-1} \varepsilon_{1}^{-m} \varepsilon_{2}^{-(1-m)} \alpha^{-\alpha}(1-\alpha)^{-(1-\alpha)} .
$$

[Proof for Proposition 4] 
If we plug equation (A9) into equation (17) and divide both sides by $k$,

$$
g_{k}-(r-n-g-\phi)=\frac{1}{k} W\left(1-\phi \frac{\eta}{W}\right)
$$

where

$$
\phi \frac{\eta}{W}=\frac{\int_{t}^{\infty} \exp \left[-\int_{t}^{s}\left(r-n-g-g_{W}\right) d v\right] d s}{\int_{t}^{\infty} \exp \left[-\int_{t}^{s}\left(r-n-g-g_{c}\right) d v\right] d s} .
$$

$g_{W}$ is the growth rate of wage. Since $W=(1-\alpha) A k^{\alpha}, g_{W}=g_{y}$. We can show that on the convergent path with $k(0)<k^{*}, g_{c}>g_{y}$ iff $\frac{R^{*}}{\theta}>\alpha(\delta+n+g) .{ }^{11}$ By (A19), $\phi \frac{\eta}{W}<1$ iff $\frac{R^{*}}{\theta}>\alpha(\delta+n+g)$. Using (39), $\lambda_{o}>0$ iff $\frac{R^{*}}{\theta}>\alpha(\delta+n+g)$.

11 See Appendix 2C in Barro and Sala-i-Martin (2004). 